\title{
Take "Wukong Chinese" as an Example to Discuss the Reform Online Teaching Chinese as a Foreign Language Under the Epidemic Crisis
}

\author{
Sichen Liu*, Mingjun Guo, Yifan Wang \\ Xi'an Shiyou University, Xi'an710065, China \\ ${ }^{*}$ Corresponding author. Email:1094971098@qq.com

\begin{abstract}
Under the influence of novel coronavirus pneumonia, teaching Chinese as a foreign language is also facing great challenges. The research object of this paper is Wukong Chinese, a domestic training institution for Chinese as a foreign language for children during the epidemic period. It analyzes the changes and adjustments of Chinese teaching under the world public health emergencies, and makes a detailed analysis of its response measures, such as retaining the teaching market and accumulating teaching resources, and make a summary of its successful experience. At the same time, as a practitioner of Chinese online education, this paper discusses whether to keep the teaching changes after the epidemic, in order to provide reference for relevant domestic Chinese education service institutions for children.
\end{abstract}

Keywords: Epidemic crisis, Online teaching, Chinese as a foreign language for children, Teaching set up.

\section{以“悟空中文”为例谈疫情危机下的线上对外汉语教学 改革 \\ 刘思宸 ${ }^{*}$ 郭明军, 王一凡}

西安石油大学, 陕西西安 710065 , 中国

“通讯作者. 屷箱：1094971098@qq. com

中文摘要

在新冠肺炎的影响下, 对外汉语教学也面临着巨大的考验, 各大汉语教学机构也纷纷转型。本文的研究对象为 疫情期间国内少儿对外汉语培训机构----四川成都汉教公司 “悟空中文” 为例，对其在世界突发公共卫生事件 下汉语教学变化调整作分析, 对其在疫情突发时刻的应对措施, 诸如: 保留教学市场、积攒教学资源等进行详 细梳理, 并对其成功经验作出总结。同时, 作为中文线上教育的实践者, 对疫情过后是否继续保留教学变化作 思考和探讨，以期为国内相关少儿中文教育服务机构提供借鉴。

关键词: 疫情危机; 线上教学; 少儿对外汉语教学机构; 教学设置. 


\section{1. 引言}

2020 年初, 新冠疫情的爆发使国内中小学的课堂 不得已改变以往的授课方式, 线上教学的方法成为了 网络教育的主流，教育领域也发生了巨大的变革，很 多学校和老师采用直播录播和文字加音频的形式, 课 后还会采用微信群、QQ 群等进行实时答疑, 极大地 提高了学习的效率, 减少了因为空间和时间而带来的 不便。与此同时, 中文在线教育尤其是少儿中文在线 教育也由此火热。中小企业还面临着机构破产、课程 转型不当, 教材混乱, 所以本文以成都的悟空中文为 例, 对主流的少儿对外汉语教学机构进行调查, 分析 出可供借鉴的教学模式。

\section{2. 疫情对 “对外汉语” 教学的影响及其相应 的反应}

\section{1. 教学对象的流失}

疫情危机下, 对外汉语教学遇到了莫大的瓶颈, 很多国家的学生因此停止了中文的学习。所以大部分 国内高校合作的孔子学院都暂停了线下授课, 相应地 孔子学院志愿者和专职教师都无法派出。因此, 国家 中外语言交流合作中心以及私立对外汉语机构开展 了线上教学模式, 但是有些国家地区达不到上网必备 的条件, 比如一些发展中国家的网速缓慢, 无法支撑 线上上课需要的网速, 不得不放弃学习中文。还有的 学生由于年龄过小, 难以集中注意力在线半小时到一 小时的学习, 因而选择停课。再有一部分学生因为平 台的原因导致课堂互动性差, 感受不到语言的沟通和 文化的学习, 中文学习很难进行。

\section{2. 教学设施欠缺}

受疫情影响, 国家或者民间的对外汉语教学都转 到了线上进行, 但是目前, 线上教育发展还不成熟, 正在逐步完善中。国内对外汉语教学机构为保证正常 上课而使用的教学平台有 ZOOM、Classin、钉钉。这 几款教学软件基本可以满足音视频播放、共享桌面、 画笔涂鸦、课件存储的要求, 但是, 受官方限制, ZOOM 现在登录需要购买账号, 所以目前不能大规模 推广使用。Classin 是目前悟空中文使用的平台, 包括 国内的 Lingoace(国内在线对外汉语的另一大机构) 也在使用, 钉钉平台目前只支持电脑端口, 所以对于 教师来说, 存在很多的使用不便, 视频互动目前也不 能满足多人同时在桌面上, 这都对教学产生了重大的 影响。

\section{3. 在线教学资源良莠不齐，难以抉择}

疫情兴起的在线教学导致教学资源过多, 纷繁复 杂, 没有一个成熟的课程设置作为参考标准, 导致了 学生难以找到合适自身水平的学习材料, 对于初学者 来说, 本应该找拼音或者简单笔画的汉字进行学习,
但是有的学生急于求成, 在线教学 APP 又鱼龙混杂, 教学体系不完善, 所以导致学生容易选择教材版本难 度过大, 这样反而使学习效率低下, 不利于中文的学 习。

\section{4. 国内对外汉语教学机构对疫情的反应}

疫情产生在互联网高度发达的今天，网络教学资 源平台和移动端应运而生, 目前课程设置较为成熟, 运营稳定的机构平台有哈兔中文、汉声中文、Italki、 Lingoace、悟空中文、Preply、Amazingtalker 等，这 些教学平台能够针对学生个性化地展开教学, 教学内 容贴合青少年儿童的心理发展, 利用碎片化的时间进 行汉语学习, 极大地便利了学生的汉语学习。与此同 时, 大大减少了疫情对于对外汉语教学事业的冲击。 同时，国家汉办的推广的线上教学也有一定成效，不 仅给国内汉语国际教育专业的学生提供了实习实践 的机会, 也最大地保留了国外汉语学习的市场。这种 互联网十的模式, 解决了现实教学存在的最大的问题 --时空问题，同时，也锻炼了教师的教学技术操作、 二语沟通能力、应对课堂突发状况处理问题的能力。

\section{3. 以 “悟空中文” 为例, 分析如何应对教学 挑战}

国内对外汉语教学机构中，“悟空中文”凭借少 儿汉语教学的独特模式赢得了一席之地, 并且目前在 欧美、大洋洲以及亚洲地区都有庞大的教学市场, 它 课件新颖、师资要求高、游戏互动有趣贴合少儿心理、 管理模式划分明确，在疫情仍然严重的局势下，很好 地化解了在线教学的一些难题。

\section{1. 教学平台的选择}

悟空中文选择的教学平台是比较常见的 Classin。 这款教学平台特点是可以进行板书、PPT、画笔、学 生上台发言等教学辅助。具体实践方面包括:

一是可进行视频录制。较以往的课堂不能重复观 看回放的特点, 线上课堂突破了这一局限, 让更多的 不处于同一时间空间段的学生可以反复观看。

二是支持云端存储。课件可以同步到平台的云端, 对于教师来说大大减少了备课查阅课件的压力，可以 直接在平台进行备课练习, 作。

而线下课堂则需要老师自己查阅资料进行 PPT 制

三是多款游戏软件设置。教师针对儿童进行的课 程设计, 自然要贴合儿童的心理发展, 借助线上教学 平台, 课件游戏充分发挥出了可操作性强、直观性性 强的特点, 比如随机针对小班课的随机选人, 私教课 的掷色子等小游戏，极大地激发了儿童的积极性。

四是文化视频资源多样化。对比以往的线下教学 模式来看，教师在线上使用文化视频资源更加频繁， 
对一些词汇比如成语故事、传统节日习俗，汉字的来 源讲解更加具有文化性, 同时, 教师本身的文化素养, 对传统文化的把握也在提升。

\section{2. 线上教学的要求}

悟空中文教师的篮选率是 3\%, 这也奠定了一个强 大的师资基础，才得以打造出高品质的课堂。具体对 老师的招聘要求大概可以归纳为:

一是教育类背景。师资大部分是国内高校本科毕 业生，专业是中国语言文字类、文学类、汉语国际教 育本专业。

二是普通话要求高。95\%的教师都必须持有普通 话二级甲等的证书才可以。

三是有汉教经验。经过搜查资料发现, 目前国内 发展较大的几个机构都需要之前从事过汉语教学的 老师, 以更好地运用平台的课件施展教学。

四是网络环境要求高。由于网络教学最突出的问 题便是网速, 而且教学平台一般需要多人互动、音视 频要求流畅、游戏、课件需要同时应用, 所以需要教 师不仅个人素质需要达标, 电脑硬件网络环境同样需 要。

五是空间环境要求高。教师在网络授课, 需要佩 戴专业的耳麦, 才能够达到良好的收音效果, 同时, 网络授课需要教师符合视频出境标准。比如: 背景板 需要是白纯色系、摄像头的清晰度要高, 台式电脑的 话需要安装外接摄像头、教师出境时要协调好和镜头 的比例问题。

\section{3. 课程分类}

悟空中文课程分类明确清晰, 很好地针对不同水 平的汉语学习者制定个性化的教学方案。其大概可以 分为主修课、精品专题课、大班直播课, 其中学生学 习最多的是主修课程。分为启蒙课、 $\mathrm{L}$ 系列的基础课 程、 $G$ 系列的进阶课程。精品专题课又分为拼音课和 成语课。大班直播课可以分为阅读课和文化课, 而且 这部分可以免费对报名的家长学生开放, 极大地提升 了学生的文化背景积累, 而且促进了报名率的转化。

\section{一是分层次培养}

目前国内对外汉语教学机构大部分针对的都是儿 童为主, 教学对象是 3--13 岁的华裔学生。面对这种 情况, 悟空中文将其分成了不同的阶段, 就主修课程 而言:

启蒙 $\mathrm{A}$ 主要的教学对象是年龄低幼或需要双语教 学, 表达不流利的学生、还没法表达出完整的词组与 句型。

启蒙 B 主要针对年龄偏低, 没有识字量, 还不能 书写, 但是听说比较流利, 能够自己说出一些词组和 句型。
$\mathrm{L}$ 系列的课程也根据识字量的不同, 掌握四会字 即听说能写能力的不同进行中文输入, 这些学生生活 中没有大量的中文输入, 听说读写也停留在日常的简 单交流, 词汇量不够丰富, 读写能力较差

$\mathrm{G}$ 系列的课程针对的教学对象是有过系统学习中 文的经历, 识字量已经达到一定程度, 中文水平较高 的学生。比如之前在国内读过小学, 或学习过部编版 的教材的学生。

\section{二是主题式培养}

(1)海外华裔的低年级的学生来说, 这种以主题 作为培养更容易激发学生的学习兴趣, 比如悟空在这 个方面就设置了针对学前儿童的必备课程, 让孩子们 在学前有足够的知识储备, 树立孩子的自信心。具体 可以分为“吃饭”“生病”“讲卫生”“数字”“我们的国家” 等方面, 既符合学生的年龄段心智发展又可以达到汉 语启蒙的效果。

(2)就海外高年级段的学生而言, 国学经典、名家 选诗、快乐拼音、书法这些主题系列课程都很适合他 们提高汉语阅读能力和拓展汉语文化知识, 而且从二 语习得角度来说, 有一定量的汉语文化背景知识的输 入, 这样学习汉语听说读写效果更好。

\section{4. 督导检查模式完善}

悟空中文的教师通过面试之后, 都需要进行第一 轮的培训磨课, 时间长达两周, 主要是就体验课的课 程反复讲练, 以达到最好的教学效果。通过之后老师 可以给学生进行体验课的教学, 之后再进行第二轮的 教学磨课, 主要针对正式课的教学培训, 这对老师的 要求会更高, 更加地强调正式课学生作业的布置与批 改, 以及当学生升级到高一级时应如何调整教学方案 以适应家长和学生的需求。在正式上开课一个月左 右, 机构会对老师进行抽查督导, 并且按语言维度是 否符合学生汉语水平、授课环节中是否边朗读边做手 势吸引学生的注意力、课堂中能否运用暗示法鼓励引 导学生, 并且在田字格书写中是否能正确描述笔画笔 顺等都做出了明确的规范。

\section{4. 悟空中文探索的成效及其借鉴意义}

悟空中文汉教公司成立五年以来，给国内众多的 汉教专业的同学或老师提供了实践成长的机会, 比对 教师们第一次和最后一次的上课录屏发现, 很多教师 都成长为了具备专业的对外汉语教学技能、有一定的 教学经验, 能自如地驾驭对外汉语课堂的汉语教师 了。

悟空中文的探索对国内目前的少儿汉语教学机构 也有很多值得借鉴的方面:

一是成熟稳定的平台

对比其他几个平台, 悟空所选用的平台网络型号 较为稳定, 多人同时登录也会较少出现延迟、闪退的 
情况，并且在微信端建立了 Classin 技术服务群，这 很好地降低了上课由于平台问题而出现的教学事故 的发生率, 更大地保障了学生的学习体验感。

二是严格把关的师资与培训

悟空中文高要求的教师篎选率让学生在体验课时 候就留下了很好的教师印象, 从而鼓励更多的人报名 学习。这对于其他同类机构来说也是一种模范与标 杆, 只有严格地对老师进行规范, 后期进行系统地线 上教学的培训, 才能达到最大的学生转化率。

\section{三是多语种模式}

作为一名对外汉语教师, 首先要熟练掌握的就是 汉语, 其次更为重要的, 在面对低龄化初学者来说, 二语尤为重要, 只有一定的媒介语的辅助, 学生才能 够听懂教学指令, 根据所给的要求说出相应的句子。 悟空中文将老师分为普通老师和双语老师以及多语 老师, 这样增大了学生的覆盖率, 扩大了学习需求范 围, 也有利于老师可以自由地选择擅长的语种进行教 学, 非常便利。

\section{四是分层次、多样化的课程设置}

在前文中已经具体介绍了悟空的课程体系分类, 这种对于不同年龄段的学生有不同的课程定位, 吸引 了很多海外的家长报名。在每一次体验课前教师都会 根据课程顾问所给的学生的具体信息进行等级测试, 然后根据相应级别的体验课进行汉语教学, 这不仅符 合了学生对应的汉语水平, 也会让家长感觉非常专 业, 顾问老师也会根据体验课的情况和教师的课堂反 馈给学生制定一个独特的学习方式, 满足了个性化学 习的要求, 而这是很多海外家长学习汉语时非常看重 的。

\section{五是多样化的互动与追踪教学}

在悟空中文的课堂上, 学生是学习的主体, 更多 的课堂互动都是老师引导, 学生完成。其中包括掷色 子游戏、计时器、定时器、作业预设、抢答环节、答 题器、小黑板、投屏模式等, 这些都是教师上课时的 “百宝箱”。同时针对笔画笔顺，悟空有拼字游戏、笔 画填空、数笔画等, 针对生词、词组教学, 悟空有拼 图游戏, 选词填空游戏、连线游戏等。在本堂课结束 之后, 老师还会布置悟空秘籍相应的作业, 多是连线、 画画、填词、写生字等。在每一个小级别完成之后还 会有阶段测试, 让老师来检查学生是否真正学会了之 前的知识, 然后才可以进入下一个级别。这种多样化 的互动课堂与追踪式的学习更加符合线上学习的要 求, 减少了因为时空距离差异大而造成的学习热度持 续性差、学完就忘等问题的发生。

\section{5. 结语}

$5 \mathrm{G}$ 时代已经到来, 大力发展互联网已经是大势所 趋, 世界各地的人们在线学汉语的模式将成为主流。 虽然疫情还未结束并且将持续常态化, 但可以预见,
人们对优质的对外汉语学习需求将不断地扩大, 线上 教学逐渐会成为最重要、最普遍、最便捷的学习方式。 悟空中文的少儿对外汉语教学模式及课程设置、教学 管理等多方面值得我们借鉴学习, 它不仅弥补了现在 对外实践机会少的缺陷, 而且也拓展了新的教学路 径, 提升了专业对口就业率。

\section{REFERENCES}

[1] Zhang Peng. Online development of Chinese language education in the UK during the epidemic period [J]. World education information, 2020,33 (07): 21-24

[2] Zhang Chengjiao, Jiang Hongjing, Lu Qiaoling. Research on the development of Chinese International Education under the background of "Internet plus" [J]. Journal of Changchun Institute of Technology (SOCIAL SCIENCES), 2019,20 (02): 108-111.

[3] Luo ronghua. Practice and exploration of "Chinese +" online Chinese Teaching [J]. Modern education science, 2019 (09): 9-13

[4] Li Yuming, Li Bingzhen, Song Hui, Bai Lesang, Liu Lening, Wu Yongyi, Li Quan, Li Quan, Chen Wen, Ren Ying, Yu, Chen, Chen mo. "COVID-19's international education in China: challenges and solutions". (talk) [J]. language teaching and research, 2020 (04): 1-11.

[5] "COVID-19's international education in China: challenges and solutions" (next) [J]. language teaching and research, 2020 (05): 1-16. 